\title{
Comprehensive 2-dimensional gas chromatography fast quadrupole mass spectrometry (GC $\times$ GC-qMS) for urinary steroid profiling: Mass spectral characteristics with chemical ionization
}

\author{
Ying Zhang, ${ }^{a}$ Herbert J. Tobias, ${ }^{a}$ Richard J. Auchus ${ }^{b \dagger}$ and J. Thomas Brenna ${ }^{a *}$
}

Comprehensive 2-dimensional gas chromatography (GC $\times$ GC), coupled to either a time of flight mass spectrometry (TOF-MS) or a fast scanning quadrupole MS (qMS) has greatly increased the peak capacity and separation space compared to conventional GC-MS. However, commercial GC $\times$ GC-TOFMS systems are not equipped with chemical ionization (CI) and do not provide dominant molecular ions or enable single ion monitoring for maximal sensitivity. A GC $\times$ GC-qMS in mass scanning mode was investigated with electron ionization (EI) and positive $\mathrm{Cl}(\mathrm{PCl})$, using $\mathrm{CH}_{4}$ and $\mathrm{NH}_{3}$ as reagent gases. Compared to El, $\mathrm{PCl}-\mathrm{NH}_{3}$ produced more abundant molecular ions and high mass, structure-specific ions for steroid acetates. Chromatography in two dimensions was optimized with a mixture of 12 endogenous and 3 standard acetylated steroids (SM15-AC) relevant to doping control. Eleven endogenous target steroid acetates were identified in normal urine based on their two retention times, and $\mathrm{EI}$ and $\mathrm{PCI}-\mathrm{NH}_{3}$ mass spectra; nine of these endogenous target steroid acetates were identified in congenital adrenal hyperplasia (CAH) patients. The difference between the urinary steroids profiles of normal individuals and those from CAH patients can easily be visually distinguished by their GC $\times$ GC-qMS chromatograms. We focus here on the comparison and interpretation of the various mass spectra of the targeted endogenous steroids. $\mathrm{PCI}^{-\mathrm{NH}_{3}}$ mass spectra were most useful for unambiguous molecular weight determination and for establishing the number of -OH by the losses of one or more acetate groups. We conclude that $\mathrm{PCI}-\mathrm{NH}_{3}$ with $\mathrm{GC} \times \mathrm{GC}$-qMS provides improved peak capacity and pseudomolecular ions with structural specificity. Copyright $\odot 2011$ John Wiley \& Sons, Ltd.

Keywords: anabolic androgenic steroids; comprehensive 2-dimensional gas chromatography; quadrupole mass spectrometry; electron impact ionization; positive chemical ionization

\section{Introduction}

Gas chromatography electron ionization mass spectrometry (GC-(EI)-MS) has been used to test for anabolic androgenic steroids (AAS) in antidoping tests since the first use of capillary columns for steroid analysis was published by Vollmin in $1972 .^{[1]}$ The development of GC-(EI)-MS showed steady progress over these years resulting in the inexpensive and robust bench-top systems in use today. However, GC-(EI)-MS analysis of complex mixtures of steroids extracted from urine is limited by separation efficiency and production of ions characteristic of the molecular weight. ${ }^{[2-9]}$ Alternatively, GC coupled to tandem MS (GC-MS/MS) has improved detection limits and used for compound identification in steroid analysis in recent years, but still requires targeted analysis. ${ }^{[10-13]}$

The development of comprehensive 2-dimensional GC (GC $\times$ GC), coupled to either a time of flight MS (TOF-MS) or a fast scanning quadrupole MS (qMS) has greatly increased the peak capacity and separation space to improve analysis of complex samples. GC $\times$ GC employs two columns in tandem with orthogonal stationary phases, where the first column separates normally ( 30-60 min) and the second column separates cryogenic trapped slices that are released after the first column very rapidly (every $2-10$ s). GC $\times$ GC generally results in an order-of-magnitude increase in separation capacity over traditional GC and an increase in signal to noise $(\mathrm{S} / \mathrm{N})$ when used with a cryogenic modulator. In recent years, GC $\times$ GC-TOFMS has been explored for steroid analysis. $^{[14-17]}$ The significantly less expensive and smaller footprint GC $\times$ GC-qMS has the advantage of additional technical capabilities, such as positive chemical ionization (PCl) and negative chemical ionization ( $\mathrm{NCl})$. $\mathrm{GC} \times \mathrm{GC}$-qMS has been successfully applied to analysis of bacterial lipids, ${ }^{[18]}$ environmental contaminants, ${ }^{[19]}$ essential oils, ${ }^{[20]}$ and gasoline ${ }^{[21]}$ using electron ionization (EI).

$\mathrm{PCl}-\mathrm{MS}$ emerged from pioneering work on ion/molecule reactions in the 1960 s by Munson and Field. ${ }^{[22]}$ It is now an optional

\footnotetext{
* Correspondence to: J. Thomas Brenna, Cornell University, Division of Nutritional Sciences, Savage Hall, Ithaca, NY 14853, USA.

E-mail: jtb4@cornell.edu

+ Current Address: University of Michigan Medical Center, 1150 W Medical Center Drive, Ann Arbor, MI, 48109, USA
}

a Cornell University, Division of Nutritional Sciences, Ithaca, NY, USA

b University of Texas Southwestern Medical Center, Dallas, TX, USA 
feature on many commercially available mass spectrometers and is performed using reagent gas plasmas to ionize sample molecules. For the generation of positive ion mass spectra, the most common reagent gases are $\mathrm{CH}_{4}, \mathrm{C}_{4} \mathrm{H}_{10}$, and $\mathrm{NH}_{3}$. In $\mathrm{PCl}$, the reagent gas is ionized by $\mathrm{El}$, followed by ion-molecule reactions that produce primary and secondary reagent ions such as $\mathrm{CH}_{5}^{+}$ and $\mathrm{C}_{2} \mathrm{H}_{5}^{+}$with $\mathrm{CH}_{4}, \mathrm{C}_{3} \mathrm{H}_{7}^{+} \mathrm{C}_{4} \mathrm{H}_{9}^{+}$with $\mathrm{C}_{4} \mathrm{H}_{10}$ and $\mathrm{NH}_{4}^{+}$with $\mathrm{NH}_{3}$, all of which are excellent proton donors. These ions react with the analyte molecules $(\mathrm{M})$, in fast acid/base reactions, or subsequently fragment to yield a limited number of product ions. ${ }^{[23]}$ $\mathrm{CH}_{4}$ is the strongest proton donor commonly used, with a proton affinity (PA) of $546 \mathrm{~kJ} / \mathrm{mol}$. For softer ionization, isobutane $\left(\mathrm{C}_{4} \mathrm{H}_{10}\right.$; $\mathrm{PA}=824 \mathrm{~kJ} / \mathrm{mol})$ and $\mathrm{NH}_{3} \quad(\mathrm{PA}=858 \mathrm{~kJ} / \mathrm{mol})$ are frequently used. ${ }^{[24]}$ Due to the lower excess energy transfer than in El, PCI produces simpler mass spectra with less molecular fragmentation and more abundant and easily identifiable molecular ions than El. $\mathrm{PCl}$ mass spectra concentrate more ion signal in fewer $\mathrm{m} / \mathrm{z}$ peaks and aids in molecular weight determination due to the intense (pseudo)-molecular ions formed from protonation $[\mathrm{M}+\mathrm{H}]^{+}$, hydride abstraction $[\mathrm{M}-\mathrm{H}]^{+}$, or adduct formation $\left[\mathrm{M}+\mathrm{NH}_{4}\right]^{+}$for ammonia that are typically observed.

Early on, Lin et al. ${ }^{[23]}$ reported $\mathrm{PCl}-\mathrm{MS}$ of free steroids using ammonia as reagent gas ((PCl-NH $\left.\left.\mathrm{NH}_{3}\right)-\mathrm{MS}\right)$ and showed simple ions that provide information about molecular weight, as well as functionalities in the molecules for cholesterol and its derivatives in 1980. Subsequently, Lusby et al. ${ }^{[2]}$ presented $\left(\mathrm{PCl}-\mathrm{NH}_{3}\right)-\mathrm{MS}$ as the method of choice for MS analysis of sterol esters after comparison of three reagent gases, $\mathrm{CH}_{4}, \mathrm{C}_{4} \mathrm{H}_{10}$, and $\mathrm{NH}_{3}$. In 1992, Rezanka et $a{ }^{\left[{ }^{[25]}\right.}$ demonstrated that more than 30 sterols in a complex sample, such as alga and yeast, can be detected using ( $\left.\mathrm{PCl}-\mathrm{NH}_{3}\right)-\mathrm{MS}$ due to its high sensitivity and abundant molecular ion information.

Here we report an evaluation of a novel commercial $\mathrm{GC} \times \mathrm{GC}$ coupled to fast qMS with $\mathrm{PCl}-\mathrm{NH}_{3}\left(\mathrm{GC} \times \mathrm{GC}-\left(\mathrm{PCl}-\mathrm{NH}_{3}\right)\right.$-qMS) to analyze complex urinary steroid extract samples with high specificity as a potentially useful technique for an untargeted screening of urinary steroid profiles. Urinary steroid preparation methods common to antidoping analysis are applied to test human urine samples.

\section{Experimental}

\section{Chemicals and standard mixtures}

High purity $\mathrm{He}(99.999 \%)$ and $\mathrm{NH}_{3}(99.9995 \%)$ were purchased from Airgas East (Salem, NH, USA). High purity $\mathrm{CH}_{4}(99.999 \%)$ was purchased from Matheson Tri-Gas (Twinsburg, OH, USA). A mixture of 15 steroids shown in Table 1 (SM15) was prepared. Twelve target endogenous steroids were used: $5 \beta$-androstan-3 $\alpha$ ol-17-one (etiocholanolone, E), $5 \alpha$-androstan-3 $\alpha$-ol-17-one (androsterone, A), 5-androsten-3 $\beta$-ol-17-one (dehydroepiandrosterone, DHEA), $5 \beta$-androstan-3 $\alpha$-ol-11, 17-dione (11-ketoetiocholanolone, $11 \mathrm{KE}$ ), $5 \alpha$-androstan-17 $\beta$-ol -3-one (dihydrotestosterone, DHT),

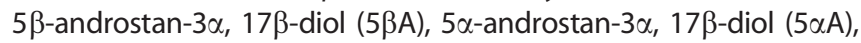
4-androsten-17 $\alpha$-ol-3-one (epitestosterone, EpiT), 4-androsten$17 \beta$-ol-3-one (testosterone, T), $5 \alpha$-androstan-3 $\alpha, 11 \beta$-diol-17-one (11 $\beta$-hydroxyandrosterone, 11-OHA), $5 \beta$-pregnane- $3 \alpha, 20 \alpha$-diol (5 $\beta$ pregnanediol, $5 \beta \mathrm{P}$ ), and $5 \beta$-estran-3 $\alpha$-ol-17-one (19-Noretiocholanolone, 19NE). One endogenous steroid normally present in urine at low concentration as a glucuronide conjugate, $5 \alpha$-androstane-3 $\beta$ ol-17-one (epiandrosterone, EpiA), and two exogenous steroids, $5 \alpha$-androstan-3 $\beta$-ol ( $5 \alpha$-androstanol) and $5 \alpha$-cholestane (Cne), were used as internal standards. Other steroid standards were:

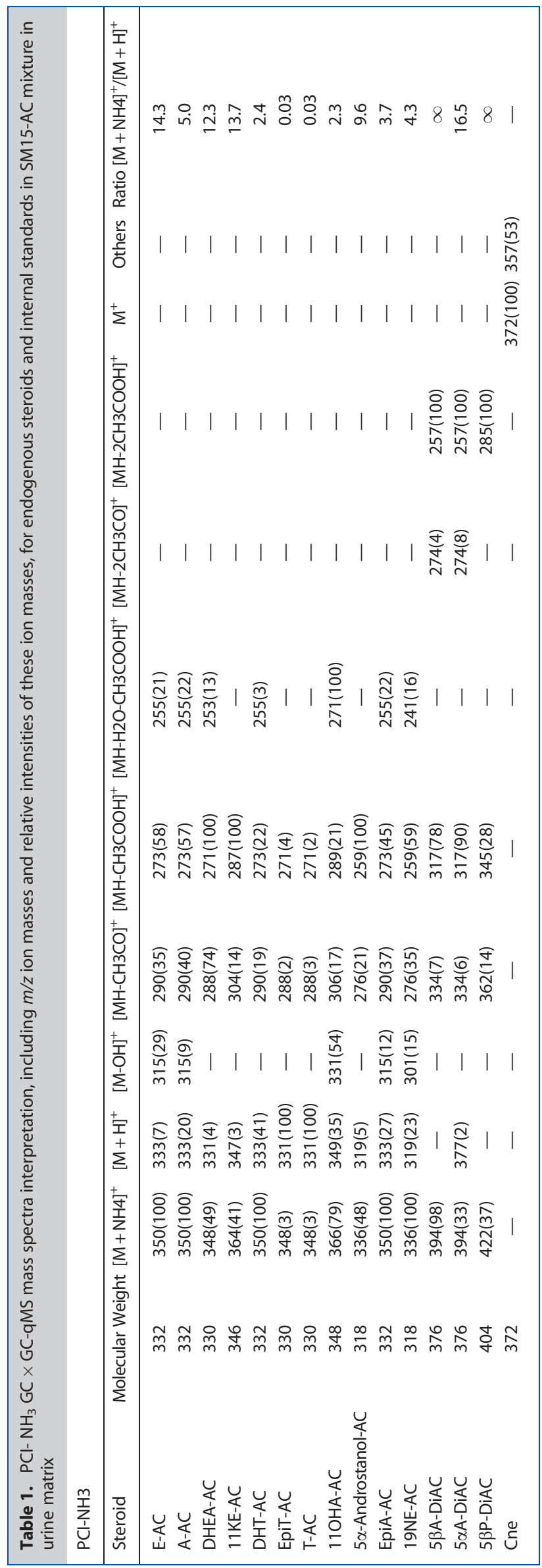


$5 \beta$-pregnane-3 $\alpha, 17,20 \alpha$-triol (pregnanetriol), 5 $\beta$-pregnane- $3 \alpha$, 17, 20 $\alpha$-triol-11-one (pregnanetriolone), 5-pregnen-3 $\beta, 17-$ diol-20one (17 $\alpha$-hydroxypregnenolone), and 4-pregnen-17-ol-3, 20-dione acetate $(17 \alpha$-progesterone-AC). All steroids were of $99 \%$ purity, and were purchased from Steraloids (Newport, RI, USA) and used without further purification. SM15 structures, molecular weight $(\mathrm{MW})$, their acetate molecular weight $\left(\mathrm{MW}_{\mathrm{AC}}\right)$ are shown in Figure 1. Chromabond $^{\circledR}$ C18 cartridges $(500 \mathrm{mg}, 6 \mathrm{ml})$ were obtained from Macherey-Nagel (Bethlehem, PA, USA). HPLC grade 2-propanol and methanol were obtained from Mallinckrodt Baker (Phillipsburg, NJ, USA). The steroid mixture was prepared in HPLC grade 2propanol at a concentration of $2 \mathrm{ng} / \mu \mathrm{l}$ for each steroid in the mixture. Pyridine, acetic anhydride, tert-butylmethylether (TBME), $\beta$-glucuronidase from Escherichia coli, sodium phosphate buffer $(0.2 \mathrm{M}, \mathrm{pH}=7)$, and potassium carbonate buffer $\left(\mathrm{K}_{2} \mathrm{CO}_{3} / \mathrm{KHCO}_{3} 1: 1\right.$, $\mathrm{W} / \mathrm{W}, 200 \mathrm{~g} / \mathrm{l}$ ) were purchased from Sigma-Aldrich (St Louis, MO, USA). All solvents and reagents were of analytical grade.

SM15 was prepared by dissolving an equal amount of each steroid ( 1 $\mathrm{mg}$ ) in $1 \mathrm{ml}$ 2-propanol and diluted to a concentration of $100 \mathrm{ng} / \mu \mathrm{l}$. A $200 \mu \mathrm{l}$ aliquot of SM15 $(100 \mathrm{ng} / \mu \mathrm{l})$ was dried under nitrogen, acetylated by adding $100 \mu \mathrm{l}$ pyridine and $100 \mu \mathrm{l}$ acetic anhydride and heated at $60^{\circ} \mathrm{C}$ for $1 \mathrm{~h}$, evaporated to dryness under nitrogen, and then reconstituted into $200 \mu \mathrm{l}$ of 2-propanol. The acetylated SM15 acetate (SM15-AC) was further diluted 50-fold to $2 \mathrm{ng} / \mu \mathrm{l}$ in 2-propanol, and $1 \mathrm{ul}$ injection into GC $\times$ GC-qMS for analysis.

\section{Urinary steroid sample preparation}

Collection and use of human urine was approved by the Institutional Review Boards of the University of Texas Southwestern Medical Center and Cornell University. Urine $(25-80 \mathrm{ml})$ was obtained from each of five normal healthy male subjects, between the ages of 20 and 50 years, and each of three congenital adrenal hyperplasia (CAH) female subjects, 23, 27, and 30 years old undergoing long-term therapeutic treatment with various combinations of hydrocortisone, fludrocortisone ( $9 \alpha$-fluorocortisol), and an oral contraceptive (Yasmin ${ }^{\circledR}$, drospirenone $3 \mathrm{mg}+$ ethinyl estradiol $0.03 \mathrm{mg}$ ). After urine collection, samples were immediately frozen at $-20^{\circ} \mathrm{C}$ and remained so until sample preparation.

A 20-ml aliquot of each urine sample was prepared for analysis. The urine samples were prepared by extracting steroid

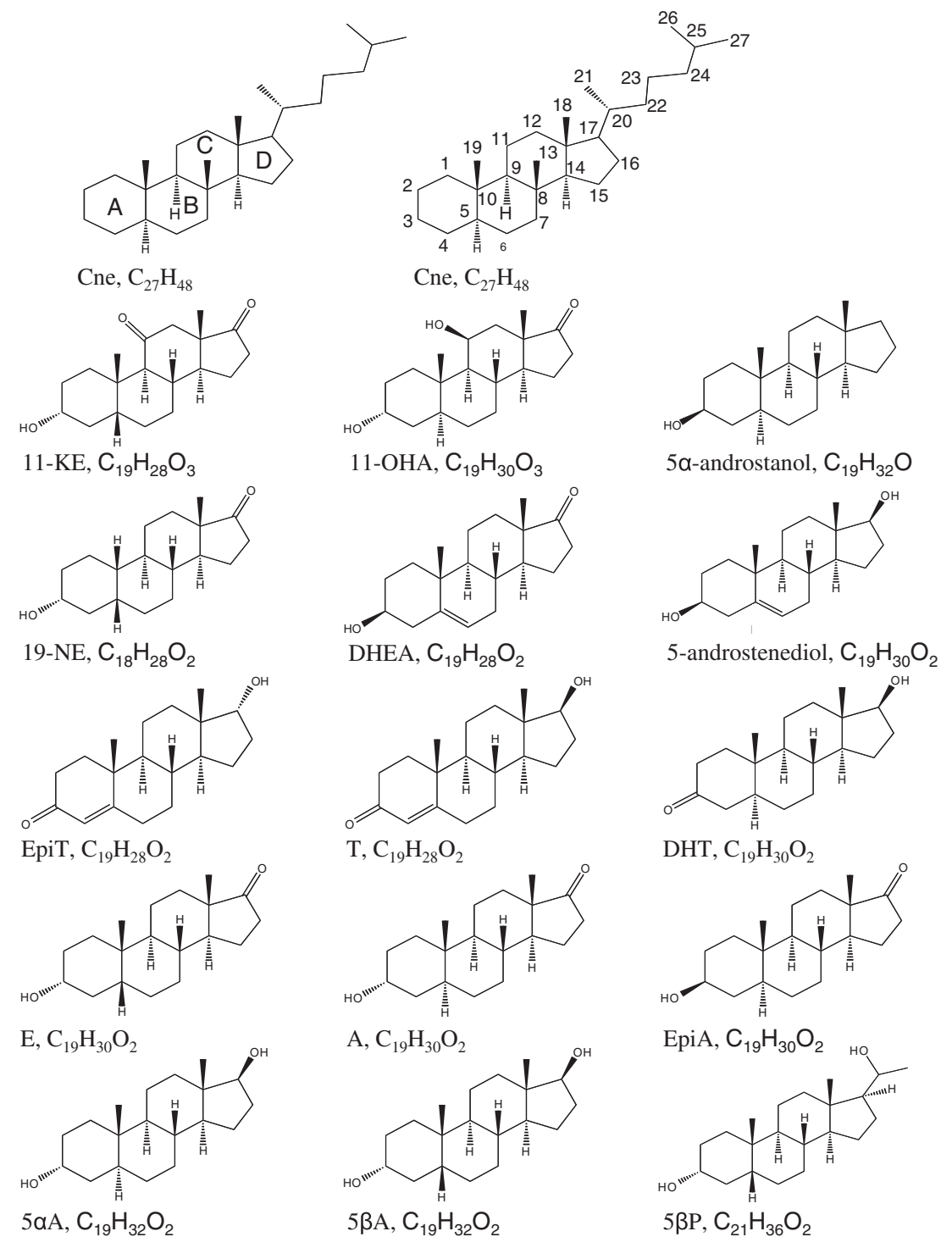

Figure 1. Chemical structures of the SM15 native steroids. 
glucuronides using solid phase extraction (SPE) and liquidliquid extraction, followed by enzymatic hydrolysis to produce free steroids and derivatized by acetylation, as described by Piper et al. ${ }^{[26]}$ and Zhang et al. ${ }^{[27]}$ No other clean-up was performed on the steroid extract samples.

Samples were spiked with an internal standard, EpiA glucuronide $(100 \mu \mathrm{l}$ of $20 \mathrm{ng} / \mu \mathrm{l})$ prior to the SPE step. Another internal standard, Cne $(100 \mu \mathrm{l}$ of $20 \mathrm{ng} / \mu \mathrm{l})$ was added quantitatively prior to injection of the samples into the GC $\times$ GC-qMS. These two internal standards were spiked into all the prepared urine extracts to account for extraction efficiency and instrumental variations.

\section{$\mathbf{G C} \times \mathbf{G C}$ configuration}

All steroid analyses were carried out on a Shimadzu GC $\times$ GC QP2010 Ultra quadrupole MS system (Shimadzu, Columbia, MD, USA) equipped with an AOC-20i autoinjector and a split/splitless inlet $\left(300^{\circ} \mathrm{C}\right)$. GC column 1 was a $30 \mathrm{~m} \times 0.25 \mathrm{~mm}$ i.d. $\times 1.0 \mu \mathrm{m}$ film ZB-1 ms (100\% dimethylpolysiloxane, Phenomenex, Torrance, CA, USA) and GC column 2 was a $1.5 \mathrm{~m} \times 0.1 \mathrm{~mm}$ i.d. $\times 0.1 \mu \mathrm{m}$ film BPX50 (50\% phenyl polysilphenylene-siloxane $50 \%$ dimethylpolysiloxane, SGE, Austin, TX, USA), both fitted in a single GC oven. The GC oven temperature program was $70^{\circ} \mathrm{C}$ for $1 \mathrm{~min}$, ramped at $40^{\circ} \mathrm{C} / \mathrm{min}$ to $300^{\circ} \mathrm{C}$, held for $35 \mathrm{~min}$, ramped at $40^{\circ} \mathrm{C} / \mathrm{min}$ to $340^{\circ} \mathrm{C}$ and held for $5 \mathrm{~min}$. Helium carrier, with an initial head pressure of $377 \mathrm{kPa}$ at $70^{\circ} \mathrm{C}$, was used at a constant flow rate of $1.3 \mathrm{ml} / \mathrm{min}$. Samples were injected into a split/splitless inlet held at $300^{\circ} \mathrm{C}$ in splitless mode. The modulation was $6 \mathrm{~s}$ using a Zoex double focusing loop modulator (Zoex Corp., Houston, TX, USA) consisting of a $1.5 \mathrm{~m} \times 0.1 \mathrm{~mm}$ i.d. capillary. The nitrogen gas cold jet was operated at $\sim 125^{\circ} \mathrm{C}$ to trap steroids, and the hot jet pulse was operated at $350^{\circ} \mathrm{C}$ for plug release.

A fused silica capillary $(1 \mathrm{~m} \times 0.1 \mathrm{~mm}$ i.d.) was used as a transfer line to the MS.

\section{MS parameters}

The samples were analyzed in the mass scanning mode at $25 \mathrm{~Hz}$ (25 full scans per second), with a scan speed of $10000 \mathrm{u} / \mathrm{s}$ and

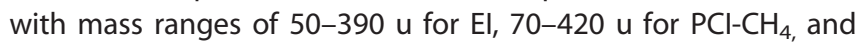
200-440 u for PCl- $\mathrm{NH}_{3}$ at a detector voltage of $0.8 \mathrm{~V}$. The ion source temperature for El was $290^{\circ} \mathrm{C}$ with El energy of $70 \mathrm{eV}$, for $\mathrm{PCl}-\mathrm{CH}_{4}$ and $\mathrm{PCl}-\mathrm{NH}_{3}$ was $250^{\circ} \mathrm{C}$. The $\mathrm{NH}_{3}$ and $\mathrm{CH}_{4}$ gas pressures were $30 \mathrm{psi}$ and $35 \mathrm{psi}$, respectively. Shimadzu GC-MS solution software version 2.53 and GC image software (Zoex Corp.), version 2.1 were used for data analysis and construction of $\mathrm{GC} \times \mathrm{GC}$ chromatograms.

\section{Results and discussions}

\section{GC $\times$ GC-qMS chromatographic separation of urinary steroids}

GC $\times$ GC-qMS chromatographic conditions were optimized using SM15-AC to achieve best separation of target steroids. Figure 2 presents a total ion chromatogram (TIC) of endogenous steroids in a urine extract analyzed by GC $\times$ GC-qMS using El (Figure 2a)

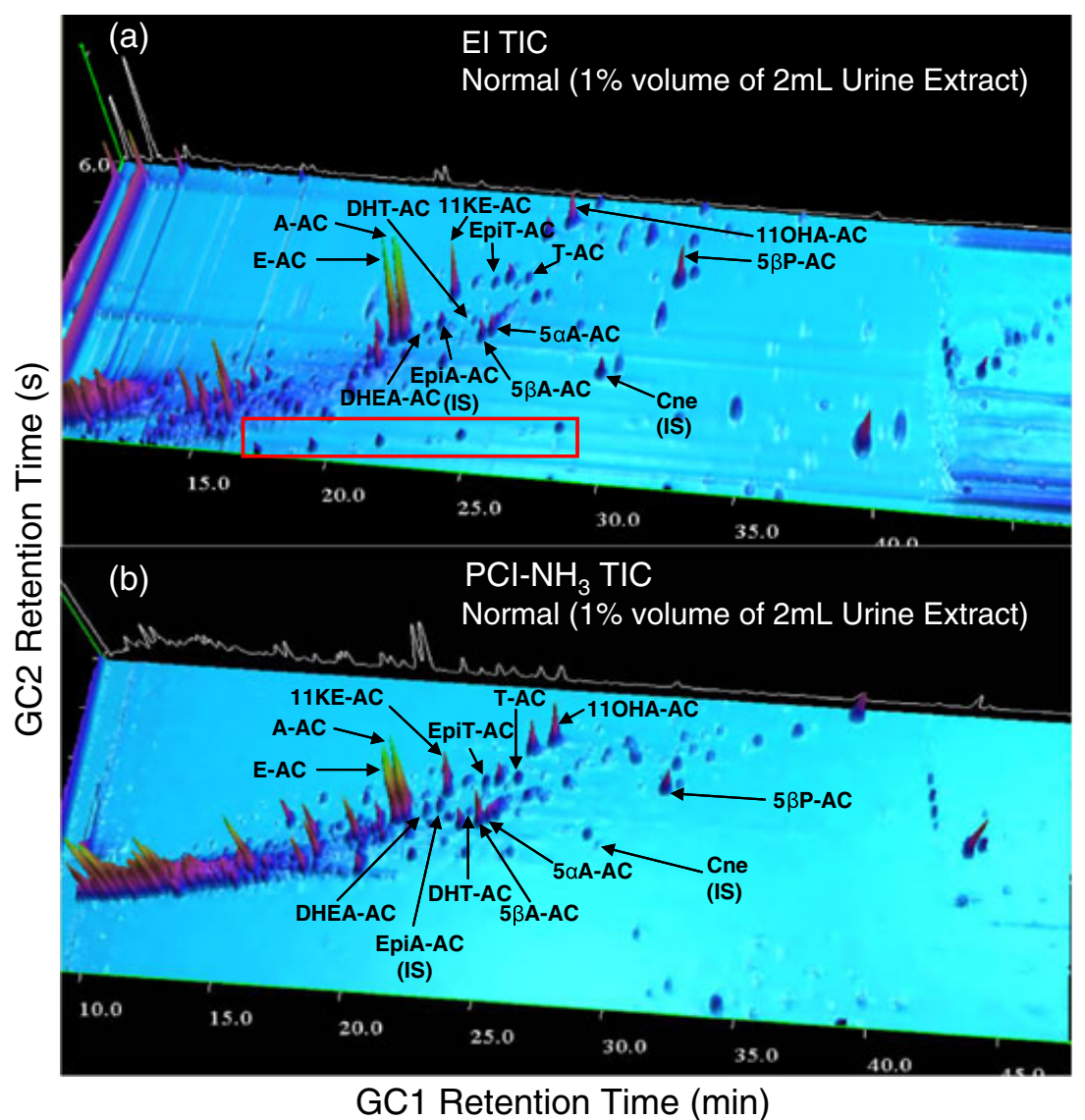

Figure 2. GC $\times$ GC-qMS total ion chromatogram (TIC) of a typical normal urine extract using (a) $\mathrm{El}$ and (b) $\mathrm{PCI}-\mathrm{NH}_{3}$. 
and $\mathrm{PCl}-\mathrm{NH}_{3}$ (Figure 2b). All target steroids are detected by $\mathrm{PCl}-$ $\mathrm{NH}_{3}$ except for $19 \mathrm{NE}$, which is seldom detected in male urine. ${ }^{[28]}$ All detected target steroids are baseline resolved, apart from DHT and $5 \alpha \mathrm{A}$-diAC which coelute with matrix interference.

$\mathrm{CAH}$ refers to autosomal recessive diseases resulting from mutations of genes for enzymes mediating the biochemical steps of production of cortisol and aldosterone from cholesterol by the adrenal glands (steroidogenesis). It involves excessive or deficient production of sex steroids and can alter development of primary or secondary sex characteristics in some affected infants, children, or adults of both genders, and early diagnosis is considered important for treatment. ${ }^{[2,30]}$ The three $\mathrm{CAH}$ patients were treated with various binary combinations of hydrocortisone, fludrocortisone, and oral contraceptive; thus, CAH symptoms and steroid metabolites were altered in unpredictable ways. Figure 3 shows a typical GC $\times$ GC-qMS analysis of endogenous steroids in an extract of urine from a female patient with $\mathrm{CAH}$, and indicates similar chromatographic separation for target endogenous steroids observed for the male athletes. In contrast to urine of healthy males, a peak is found at the retention times for $19 \mathrm{NE}-\mathrm{AC}$, an endogenous steroid which is occasionally found in women's urine, and may be due to degradation of E. Figure 3c shows an EIC $(m / z 259,276,336)$ characteristic of 19-nor steroid acetates including 19NE. The inset shows that $19 N E-A C$, identified by its mass spectrum and retention time, is baseline resolved from two adjacent peaks presumed to be isomers of $19 \mathrm{NE}-\mathrm{AC}$ based on their similar mass spectra.

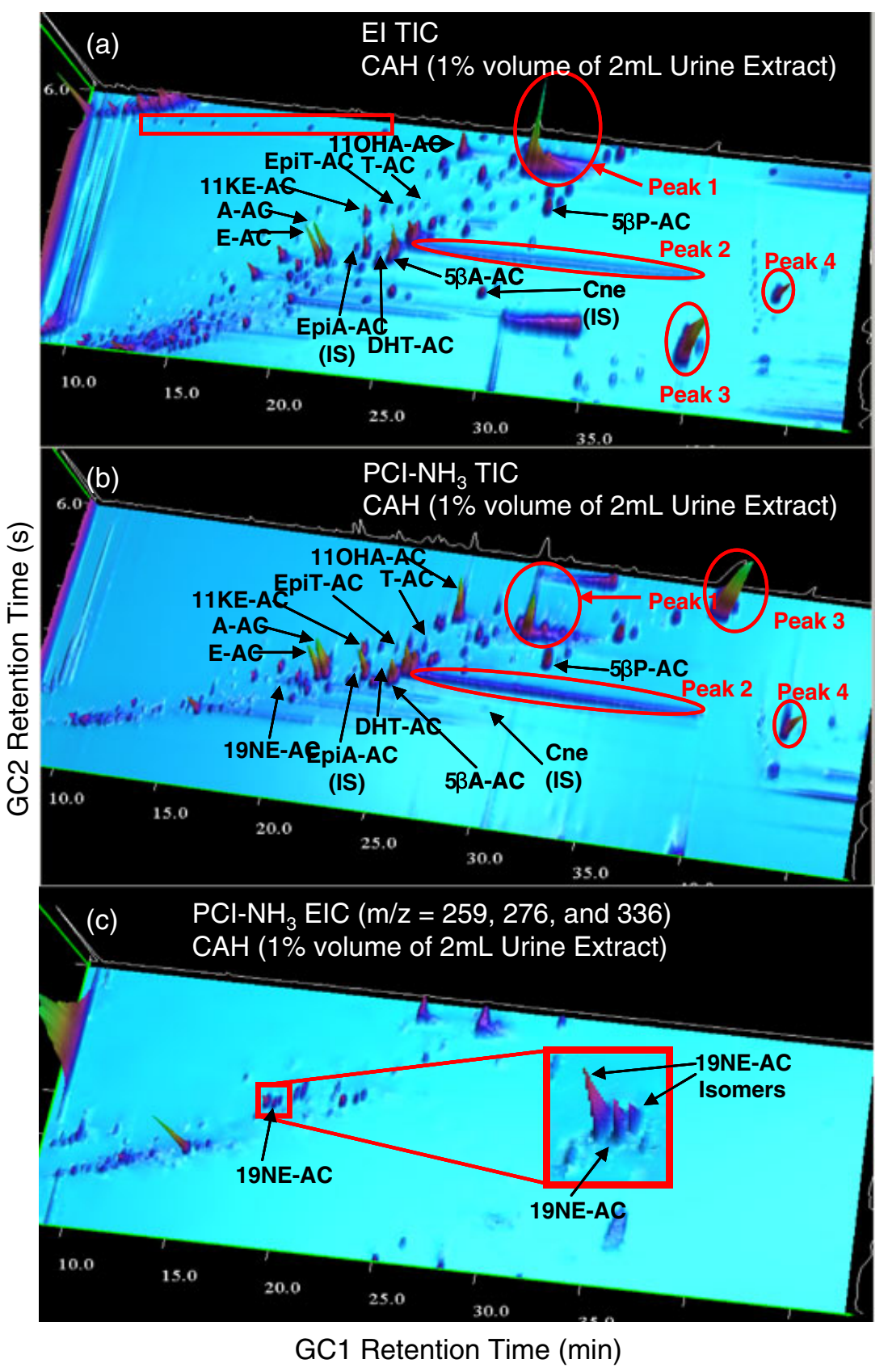

Figure 3. $\mathrm{GC} \times \mathrm{GC}$-qMS TIC of (a) El and (b) $\mathrm{PCl}-\mathrm{NH}_{3}$ in a typical CAH patient urine extract, and the $\mathrm{PCI}_{-} \mathrm{NH}_{3}$ (c) extracted ion chromatogram (EIC, $m / z=259,276,336)$. 
The TIC chromatographic patterns for the five normal urine samples and the three CAH urine samples are generally consistent within each group, reflecting expected inter-individual variability in absolute steroid concentrations. A dramatic difference is apparent between the TIC steroid patterns (using both $\mathrm{El}$ and $\mathrm{PCl}-\mathrm{NH}_{3}$ ) of normal urine and $\mathrm{CAH}$ urine by comparison of the $\mathrm{GC} \times \mathrm{GC}$-qMS chromatograms presented in Figures 2 and 3. Obvious manifestations of this difference lie in a few large peaks as labelled peak 1, peak 2, peak 3, and peak 4 in red circles as shown in Figures $3 a$ and $3 b$. Peaks 1, 2, and 4 are not found in normal urine, while peak 3 is at higher concentration than normal urine. From $\mathrm{PCl}-\mathrm{NH}_{3}$ mode, their molecular weight (MW) and number of -OH groups was readily apparent; peak 1 has a MW $=376 \mathrm{amu}$ and $2-\mathrm{OH}$ groups, and peak 2 has a $\mathrm{MW}=342 \mathrm{amu}$ and one $-\mathrm{OH}$ group. The MW of peaks 3 and 4 are uncertain because of the limited $\mathrm{PCl}-\mathrm{NH}_{3}$ mass scan range, $\mathrm{m} / \mathrm{z} 220-440$. Based on the loss of acetates in other spectra, a plausible MW of peak 3 is $m / z$ 462 amu ( $3-\mathrm{OH})$; two -OHs for peak 3 would not match observed losses. The peak 4 mass spectrum (not shown) is consistent with $\mathrm{MW}=476 \mathrm{amu}(3-\mathrm{OH})$ or $\mathrm{MW}=416 \mathrm{amu}(2-\mathrm{OH})$. CAH is usually associated with 21-hydroxylase deficiency (21-HOD), and diagnosis is by measurement of elevated urinary $17 \alpha$-hydroxyprogesterone metabolites pregnanetriol and pregnanetriolone, and as well as 17-ketosteroids such as $\mathrm{A}, \mathrm{E}, 11-\mathrm{KE}, 11-\mathrm{OHA}$ and DHEA, present in our SM15 mixture. ${ }^{[29-33]}$ Our results show no obvious elevation of the 17-ketosteroids in the $\mathrm{CAH}$ urine samples. Three acetylated steroid standards, pregnanetriol-AC (MW $=462,3-A C$ ), pregnanetriolone- $A C$ ( $M W=476,3-A C)$, and $17 \alpha$-hydroxypregnenolone-AC ( $M W=416,2-A C)$ have the same MWs as estimated for the unknown peaks 3 and 4 assuming all $-\mathrm{OH}$ groups are amenable to acetylation. They were investigated using El mode; however, none eluted within our GC $\times \mathrm{GC}$ temperature program. The precursor $17 \alpha$-progesterone, normally measured in serum, also did not elute as the acetate under our chromatographic conditions. Peak 2 has a single unique mass spectrum and is thus one long tailing compound. The cause of this chromatographic phenomenon is not clear, but may be due to column overloading for this compound. These unexpected large peaks and bands are consistent and reproducible in the other two CAH samples and their structures have not yet been positively identified. However, the untargeted nature of the technique, where full mass scans are available at every pixel provides abundant structural information without

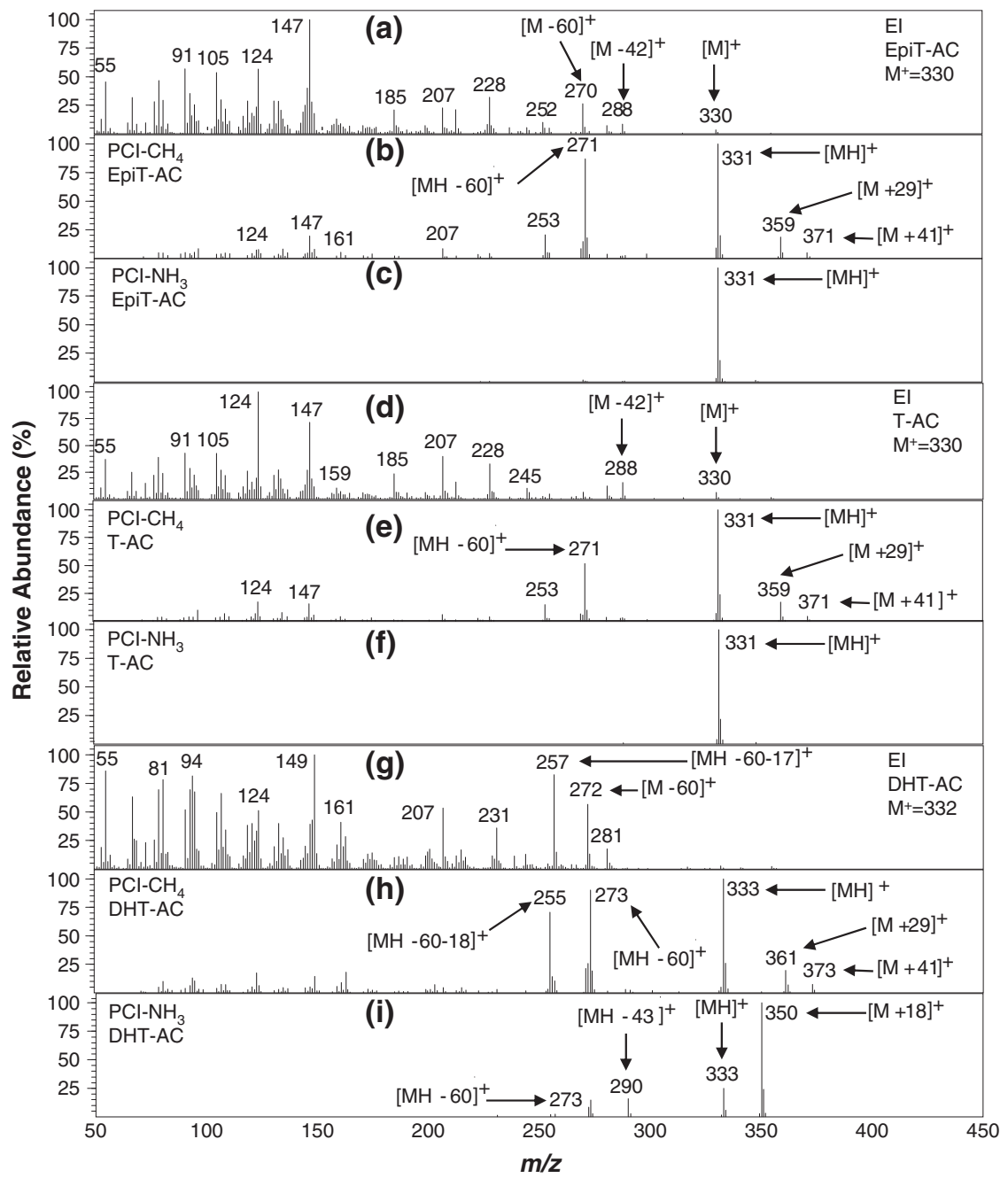

Figure 4. EpiT-AC, T-AC (in normal urine extract), and DHT-AC (in SM15-AC standard) mass spectra acquired using (a, $d, g$ ) El (mass range $m / z$ 50-390 amu), (b, e, h) PCl with methane reagent gas $\left(\mathrm{PCl}^{-}-\mathrm{CH}_{4}\right)$ (mass range $\left.\mathrm{m} / \mathrm{z} 70-420 \mathrm{amu}\right)$, and $(\mathrm{c}, \mathrm{f}, \mathrm{i}) \mathrm{PCl}$ with ammonia reagent gas $\left(\mathrm{PCl}-\mathrm{NH}_{3}\right)(\mathrm{mass}$ range $\mathrm{m} / \mathrm{z} 220-440 \mathrm{amu})$. $\mathrm{PCl}-\mathrm{NH}_{3}$ results in a very strong relative intensity for the $\mathrm{MW}+18\left(\left[\mathrm{M}+\mathrm{NH}_{4}\right]^{+}\right)$or $\mathrm{MH}^{+}$mass ion, providing unambiguous assignment of molecular weight identification. 
requiring reanalysis, as is discussed below. An advantage of GC $\times$ $\mathrm{GC}$ is that the peak patterns can be easily visualized by $2 \mathrm{D}$ contour plots or 3D plots, which could define steroid patterns suggestive of certain clinical maladies, such as endrocrinological disorders, and is a rapid visual way to monitor the effects of medical treatments or changes in an individuals metabolic processes due to nefarious doping practices. Following temporal changes in urinary profiles via the biological passport concept is likely to be useful as a non-targeted approach to detect use that influence steroid profiles. ${ }^{[34,35]}$

In reference to the chromatograms in Figures, 2a, 2b, 3a, and $3 \mathrm{~b}$, automatic peak detection of components using $\mathrm{PCl}-$ $\mathrm{NH}_{3}$ appears to be more specific than using El due to the nature of protonation by reagent $\mathrm{NH}_{3}$ gas, where a total of approximately 1800 and 1200 peaks (i.e. compounds) were detected using $\mathrm{El}$ and $\mathrm{PCl}-\mathrm{NH}_{3}$, respectively, in both urine samples. For instance, the hydrocarbons highlighted in the red box in Figure 2a are detected in El but not detected in $\mathrm{PCl}-\mathrm{NH}_{3}$, thereby producing a cleaner and more specific chromatogram. This is advantageous and suitable for steroid detection in complex urine matrices since endogenous steroids generally have functional groups $(-\mathrm{OH} /-\mathrm{C}=\mathrm{O})$ with higher proton affinity (PA) than $\mathrm{NH}_{3}$, resulting in efficient ionization using $\mathrm{PCl}-\mathrm{NH}_{3}$.

\section{PCI mass spectra}

The El, $\mathrm{PCl}-\mathrm{CH}_{4}$, and $\mathrm{PCl}-\mathrm{NH}_{3}$ mass spectra (MS) for the twelve target endogenous acetylated steroids detected in urine and other steroids in SM15-AC are presented in Figures 4-8. Generally, the El MS of all steroid acetates are dominated by fragments with most signals concentrated at low masses and little to no molecular ion signal, precluding molecular weight determination of unknowns. On the other hand, the $\mathrm{PCl}^{-\mathrm{NH}_{3}} \mathrm{MS}$ generally contain abundant (pseudo)molecular ion signals and a few high mass fragment ions that are easily interpretable for structural information, while $\mathrm{PCl}-\mathrm{CH}_{4}$ MS contain similar useful ion signals in many cases. $\mathrm{PCl}-\mathrm{NH}_{3}$, with its high $\mathrm{PA}\left(\sim 870 \mathrm{~kJ} / \mathrm{mol}^{24}\right)$ and low energy transfer in ion-molecule reactions, forms abundant adduct $\mathrm{m} / \mathrm{z}$ ions $\left[\mathrm{M}+\mathrm{NH}_{4}\right]^{+}$for compounds with many electronegative functional groups, as well as protonated molecular ions $[\mathrm{MH}]^{+}$, which together (difference of 17 mass units) confirm unambiguous molecular weight determination. The acetylating of the steroids assists in functional group information where abundant fragments associated with the acetate loss are easily identified and indicate the number of hydroxyl groups present in the native (underivatized) steroid. These fragments were manifested as single acetate loss ions $\left[\mathrm{MH}-\mathrm{CH}_{3} \mathrm{COOH}\right]^{+}\left(\right.$or $[\mathrm{MH}-60]{ }^{+}$),

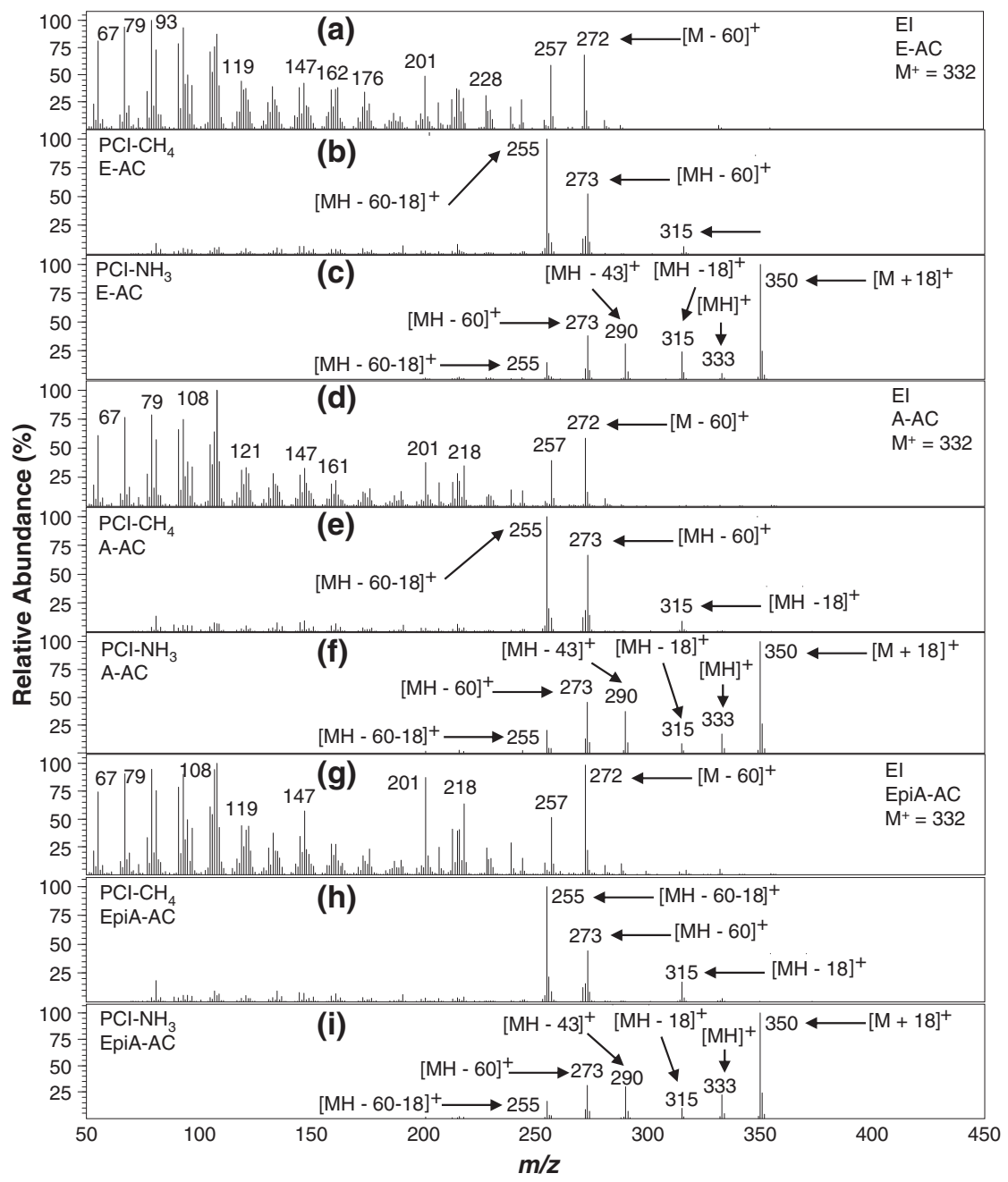

Figure 5. $E-A C, A-A C$ (in normal urine extract), and EpiA-AC (in SM15-AC standard) mass spectra, acquired using (a, d, g) El (mass range $m / z$ 50-390 amu), (b, e, h) PCl-CH (mass range $\mathrm{m} / \mathrm{z}$ 70-420 amu), and (c, f, i) PCI- $\mathrm{NH}_{3}$ (mass range $\mathrm{m} / \mathrm{z} 220-440 \mathrm{amu}$ ). 


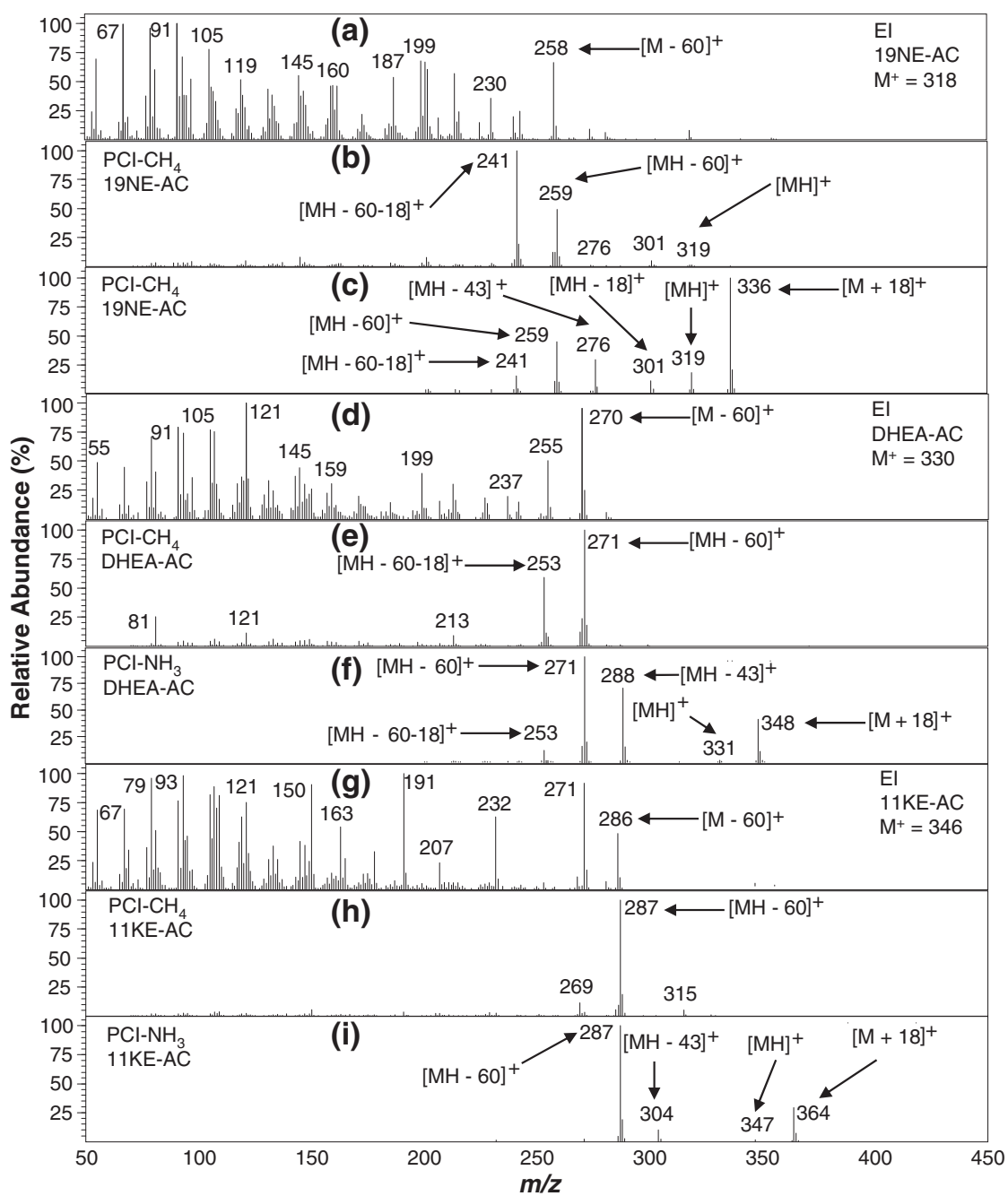

Figure 6. $19 \mathrm{NE}-\mathrm{AC}$ (in SM15-AC standard), DHEA-AC and $11 \mathrm{KE}-\mathrm{AC}$ (in normal urine extract) mass spectra acquired using (a, $\mathrm{d}, \mathrm{g}$ ) El(mass range $\mathrm{m} / \mathrm{z}$ 50-390 amu), (b, e, h) $\mathrm{PCl}^{-C_{4}}$ (mass range $\mathrm{m} / \mathrm{z}$ 70-420 amu), and (c, f, i) $\mathrm{PCl}^{-N_{H}}$ (mass range $\mathrm{m} / \mathrm{z}$ 220-440 amu).

partial acetate loss ions $\left[\mathrm{MH}-\mathrm{CH}_{3} \mathrm{CO}\right]^{+}$(or $\left.[\mathrm{MH}-43]^{+}\right)$, and double acetate loss ions $\left[\mathrm{MH}-2 \times \mathrm{CH}_{3} \mathrm{COOH}\right]^{+}\left(\right.$or $[\mathrm{MH}-120]^{+}$). In addition, these signals are often associated with water loss ions such as $[\mathrm{MH}-18]^{+}$and $[\mathrm{MH}-60-18]^{+}$. $\mathrm{PCl}-\mathrm{CH}_{4}$ produced some of the same acetate loss ions; however, seldom produced any (pseudo) molecular ions. The El process also produced acetate loss ions in the form of $[\mathrm{M}-60]^{+}$.

All the isomeric steroids in SM15 can be differentiated by GC $\times$ GC retention times, and in some cases, by their mass spectra. Figure 1 depicts the structures of all the steroids analyzed in this work and shows the nomenclature of rings and position numbers in the steroid perhydrocyclopentanophenanthrene system, using Cne as the model. $\mathrm{H}, \mathrm{CH}_{3}, \mathrm{OH}$, and $\mathrm{CH}_{3} \mathrm{COO}$ groups that lie above the plane of the ring system are drawn with solid wedges and designated as $\beta$ substituents, while those that lie below the plane are drawn with dashed wedges and designated as $\alpha$ substituents, and are important for stereochemical designations. For instance, EpiT-AC and T-AC are diastereoisomers that differ only at the 17 $\mathrm{CH}_{3} \mathrm{COO}$ position, where EpiT-AC is $17 \alpha$ and T-AC is $17 \beta$ (Figure 1 ). In fact, as shown in Figure $4 \mathrm{C}$ and $4 \mathrm{f}$, EpiT-AC and T-AC are the only steroids that resulted in an $\mathrm{MS}$ (using $\mathrm{PCl}-\mathrm{NH}_{3}$ ) where practically all signal appeared as a single $\mathrm{m} / \mathrm{z}$ ion, the $[\mathrm{MH}]^{+}$ion at $m / z 331$, which is advantageous for increased sensitivity when targeted SIM would be performed. In the $\mathrm{PCI}-\mathrm{NH}_{3}$ process, the protonation of a substrate molecule under $\mathrm{PCl}-\mathrm{NH}_{3}$ conditions is measurable only if its proton affinity (PA) is greater than that of $\mathrm{NH}_{3}{ }^{[24]}$ Thus here, the ions characteristic of the intact steroid acetate molecule depend upon the PA of the molecule. Westmore et al. ${ }^{[24]}$ reported that when $787 \mathrm{~kJ} / \mathrm{mol}<\mathrm{PA}$ (analyte) PA $\left(\mathrm{NH}_{3}\right),\left[\mathrm{M}+\mathrm{NH}_{4}\right]^{+}$will be observed; when PA (analyte) $>$PA $\left(\mathrm{NH}_{3}\right)$, both $\left[\mathrm{M}+\mathrm{NH}_{4}\right]^{+}$and $[\mathrm{MH}]{ }^{+}$can be formed, with the $\left[\mathrm{M}+\mathrm{NH}_{4}\right]^{+} /[\mathrm{MH}]^{+}$ratio decreasing as PA (analyte) increases. In Table 1, EpiT-AC and T-AC have the lowest $\left[\mathrm{M}+\mathrm{NH}_{4}\right]^{+} /[\mathrm{MH}]^{+}$ ratio $(=0.03)$, which indicate their PA are the largest in SM15-AC. This could be explained by their unique conjugated ketone group which stabilizes the molecule, making it resistant to deprotonation (more basic), and resulting in more intense protonation by the reagent gas; as a result $[\mathrm{MH}]^{+}$was produced almost exclusively over $\left[\mathrm{M}+\mathrm{NH}_{4}\right]^{+}$.

On the other hand, DHT-AC has the structure of T-AC, except the $A$ ring is saturated (i.e. no double bond). This difference is reflected in the $\mathrm{PCl}-\mathrm{CH}_{4}$ and $\mathrm{PCl}-\mathrm{NH}_{3} \mathrm{MS}$ (Figures $4 \mathrm{~h}$ and $4 \mathrm{i}$ ), where the $[\mathrm{MH}]{ }^{+}(\mathrm{m} / \mathrm{z} 333)$ is greater than for EpiT-AC and T-AC by 2 mass units; however, the $\mathrm{PCl}-\mathrm{NH}_{3}$ MS of DHT contains relatively more $\left[\mathrm{M}+\mathrm{NH}_{4}\right]^{+}$signal $\left(\left[\mathrm{M}+\mathrm{NH}_{4}\right]^{+} /[\mathrm{MH}]^{+}=\right.$ 2.4) and demonstrates how a structural difference can alter 


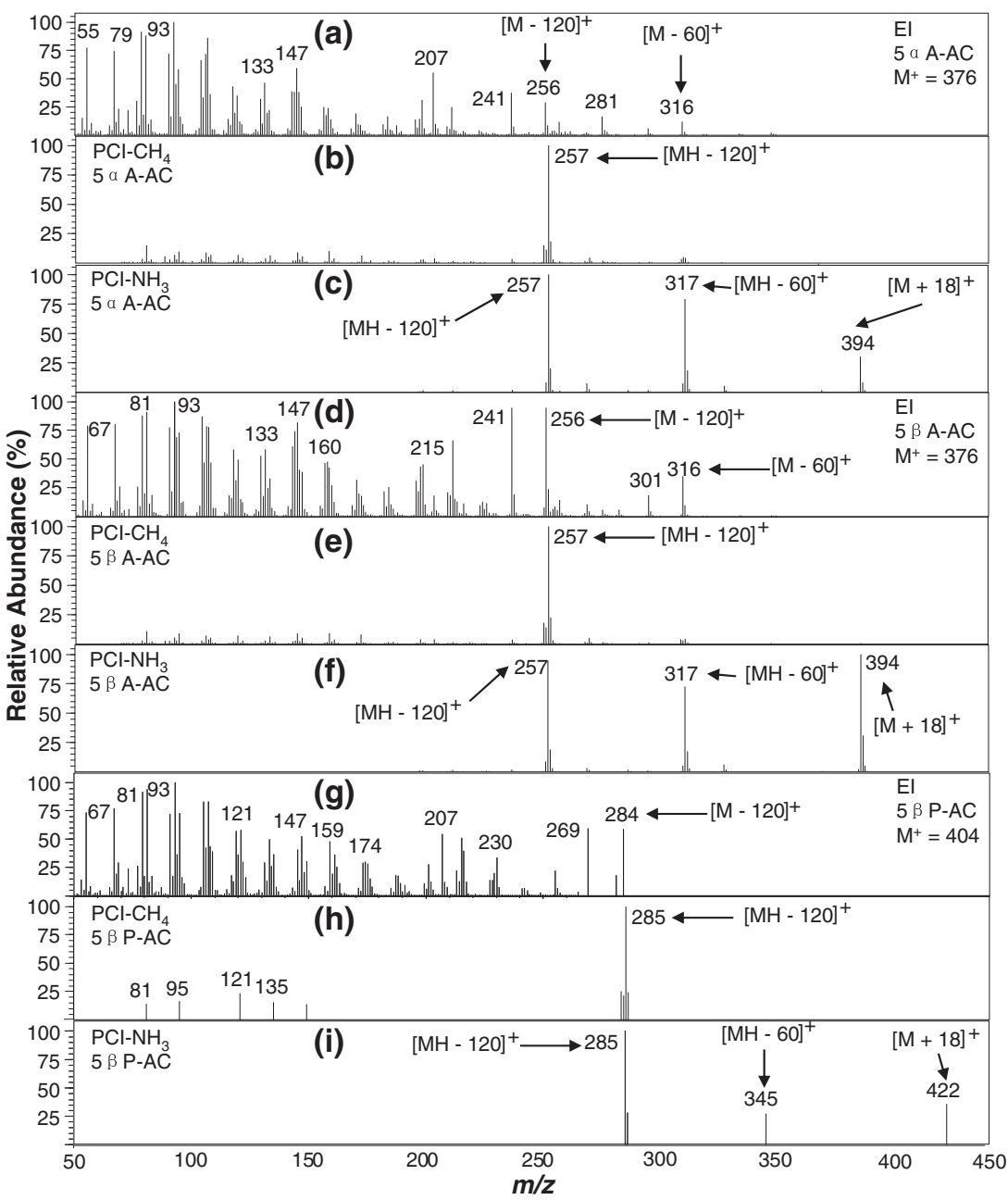

Figure 7. $5 \alpha \mathrm{A}-\mathrm{DiAC}, 5 \beta \mathrm{A}-\mathrm{DiAC}$, and $5 \beta \mathrm{P}-\mathrm{DiAC}$ mass spectra in normal urine extract acquired using $(\mathrm{a}, \mathrm{d}, \mathrm{g}) \mathrm{El}(\mathrm{mass}$ range $\mathrm{m} / \mathrm{z} 50-390 \mathrm{amu}),(\mathrm{b}, \mathrm{e}, \mathrm{h})$ $\mathrm{PCl}-\mathrm{CH}_{4}$ (mass range $m / z$ 70-420 amu), and (c, f, i) $\mathrm{PCl}-\mathrm{NH}_{3}$ (mass range $m / z$ 220-440 amu).

the $\mathrm{PCl}-\mathrm{NH}_{3}$ process. Although EpiT-AC and T-AC cannot be differentiated by their $\mathrm{PCl}-\mathrm{NH}_{3}$ MS alone, a consistently stronger $\mathrm{m} / \mathrm{z} 147$ than $\mathrm{m} / \mathrm{z} 124$ ion signal for EpiT-AC in the El (Figures $4 \mathrm{a}$ and $4 \mathrm{~d}$ ) and $\mathrm{PCl}-\mathrm{CH}_{4}$ MS (Figures $4 \mathrm{~b}$ and $4 \mathrm{e}$ ) can be used with their substantially different $\mathrm{GC} \times \mathrm{GC}$ retention times to provide confident assignments.

$\mathrm{PCl}-\mathrm{NH}_{3} \mathrm{MS}$ of EpiT-AC (Figure 4c) and T-AC (Figure 4f) does not provide functional group information, but the $\mathrm{PCl}-\mathrm{CH}_{4}$ does (Figures $4 \mathrm{~b}$ and $4 \mathrm{e})$, where in addition to a $[\mathrm{MH}]^{+}$ion $(\mathrm{m} / \mathrm{z} 331)$, a [MH-60] ${ }^{+}$ion $(\mathrm{m} / \mathrm{z} 271)$ due to a loss of a complete acetate group, reveals the steroids to be monoacetates or have a single hydroxyl group in their native state. Presumably due to its saturated ring system, both $\mathrm{PCl}-\mathrm{CH}_{4}$ (Figure $4 \mathrm{~h}$ ) and $\mathrm{PCI}-\mathrm{NH}_{3} \mathrm{MS}$ (Figure 4i) of DHT-AC provide fragment ions that reveal the presence of a single acetate group. EpiT-AC, T-AC, and DHT-AC are the only steroid acetates in SM15 that contain a ketone group at position 3 and for which $\mathrm{PCl}-\mathrm{CH}_{4}$ produced a $[\mathrm{MH}]^{+}$ion and methane cluster adduct ions $\left[\mathrm{M}+\mathrm{C}_{2} \mathrm{H}_{5}\right]^{+}\left(\right.$or $\left.[\mathrm{M}+29]^{+}\right)$and $\left[\mathrm{M}+\mathrm{C}_{3} \mathrm{H}_{5}\right]^{+}\left(\right.$or $\left.[\mathrm{M}+41]^{+}\right) ;\left[\mathrm{M}+\mathrm{CH}_{5}\right]^{+}\left(\right.$or $\left.[\mathrm{M}+17]^{+}\right)$adduct ions are not observed.

$\mathrm{E}-\mathrm{AC}$ and $\mathrm{A}-\mathrm{AC}$ are isomers at one ring junction (A/B) position, where the hydrogen is $5 \beta$ and $5 \alpha$ (Figure 1 ), respectively, resulting in very different structural configurations. The $A / B$ ring structure is cis (the A ring is angled out of the plane of figure) when the 5 position $\mathrm{H}$ is $\beta(5 \beta)$, and trans when $5 \alpha$ (the $A$ ring in the plane of the figure). Moreover, EpiA-AC is an isomer of $A-A C$, where the functional group (in this case $A C$ ) is $3 \beta$ and $3 \alpha$, respectively. The most notable comparison of these three steroids is that each of their $\mathrm{El}, \mathrm{PCl}-\mathrm{CH}_{4}$ and $\mathrm{PCl}-\mathrm{NH}_{3} \mathrm{MS}$ has generally the same pattern for all three (Figures $5 \mathrm{a}, 5 \mathrm{~d}, 5 \mathrm{~g}$ ). $\mathrm{PCl}-\mathrm{CH}_{4}$ (Figures 5b, 5e, 5h) provides no (pseudo)molecular ion, but does result in acetate loss [MH-60] ${ }^{+}$ions $(\mathrm{m} / \mathrm{z} 273)$ aiding in molecular weight assignment, when used along with the $[\mathrm{MH}-18]^{+}$ ions $\left(\mathrm{m} / \mathrm{z}\right.$ 315) indicating a 42 mass loss. $\mathrm{PCl}-\mathrm{NH}_{3}$ results in unambiguous molecular weight information through a 17 mass loss observed by the pair of $[\mathrm{MH}]{ }^{+}(\mathrm{m} / \mathrm{z} 333)$ and $\left[\mathrm{M}+\mathrm{NH}_{4}\right]^{+}$ $(\mathrm{m} / \mathrm{z} 350)$ ion signals, in addition to structural information through acetate loss [MH-60] ${ }^{+}$ions $(\mathrm{m} / \mathrm{z} 273)$ indicating a monoacetate (Figures $5 c, 5 f, 5 i)$. A-AC and EpiA-AC cannot be easily differentiated through either MS; however, $\mathrm{PCI}-\mathrm{NH}_{3}$ can be used to differentiate E-AC and A-AC through the $\left[\mathrm{M}+\mathrm{NH}_{4}\right]^{+} /[\mathrm{MH}]^{+}$ ratio which is 14.3 and 5, respectively, as shown in Table 1. The $\mathrm{PCl}-\mathrm{NH}_{3} \mathrm{MS}$ of the remaining endogenously relevant monoacetates (19NE-AC, DHEA-AC, 11KE-AC) also provided molecular weight and acetate group information as shown in Figures , 6c, $6 f$, and $6 \mathrm{i}$, respectively.

Two of the three analyzed diacetates, $5 \beta A$-diAC and $5 \alpha \mathrm{A}$-diAC, are cis/trans isomers at the $A / B$ ring junction at position 5 , 


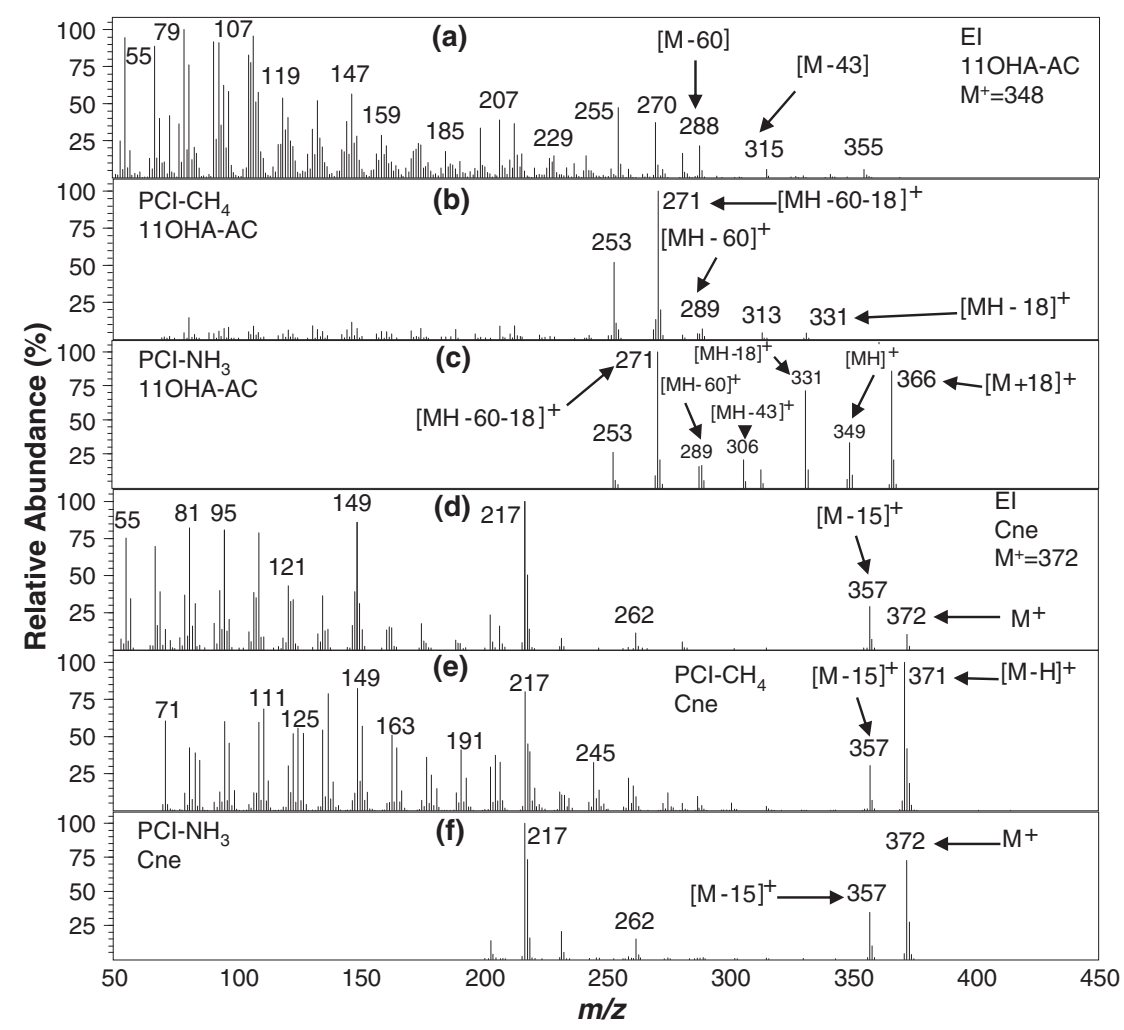

Figure 8. $11 \mathrm{OHA}-\mathrm{AC}$ (in normal urine extract) and Cne (in SM15-AC standard) mass spectra acquired using (a, d) El (mass range $\mathrm{m} / \mathrm{z} 50-390 \mathrm{amu}$ ), (b, e) $\mathrm{PCl}^{-} \mathrm{CH}_{4}$ (mass range $\mathrm{m} / \mathrm{z} 70-420 \mathrm{amu}$ ), and (c, f) PCl- $\mathrm{NH}_{3}$ (mass range $\mathrm{m} / \mathrm{z} 220-440 \mathrm{amu}$ ).

respectively, while $5 \beta \mathrm{P}$-diAC is $\mathrm{A} / \mathrm{B}$ cis at position 5 . Interestingly, $\mathrm{PCl}-\mathrm{CH}_{4}$ yields primarily the $[\mathrm{MH}-120]^{+}$ion for all three diacetates at $\mathrm{m} / \mathrm{z} 257$ for $5 \alpha \mathrm{A}$-diAC and $5 \beta \mathrm{A}$-diAC (Figures $7 \mathrm{~b}$ and $7 \mathrm{e}$ ) and $\mathrm{m} / \mathrm{z} 285$ for $5 \beta \mathrm{P}$-diAC (Figure $7 \mathrm{~h}$ ); these ions are less useful for molecular weight and functional group information. In contrast, PCl- $\mathrm{NH}_{3}$ (Figures $7 \mathrm{c}, 7 \mathrm{f}, 7 \mathrm{i}$ ) provides strong adduct $\left[\mathrm{M}+\mathrm{NH}_{4}\right]^{+}$, single acetate loss $[\mathrm{MH}-60]^{+}$, and double acetate loss $[\mathrm{MH}-120]^{+}$ ions, together making molecular weight determination and functional group assignment unambiguous. Alternatively, the native 11-OHA is a steroid diol that was derivatized to form a monoacetate (110HA-AC; Steraloids Inc., Newport, RI, USA) rather than a diacetate, which is interpretable and verified in the $\mathrm{PCl}-\mathrm{NH}_{3}$ MS (Figure $8 \mathrm{c}$ ), with the presence of (pseudo) molecular weight ions $\left[\mathrm{M}+\mathrm{NH}_{4}\right]^{+}\left(\mathrm{m} / \mathrm{z}\right.$ 366) and $[\mathrm{MH}]^{+}(\mathrm{m} / \mathrm{z} 349)$ and partial $[\mathrm{MH}-43]^{+}$and full $[\mathrm{MH}-60]^{+}$single acetate loss ions. Otherwise, molecular weight is not directly obtained from the $\mathrm{PCl}-\mathrm{CH}_{4} \mathrm{MS}$ (Figure $8 \mathrm{~b}$ ), but it does reveal evidence of just one acetate group loss when comparing the $[\mathrm{MH}-60]^{+}$and $[\mathrm{MH}-18]^{+}$ ions.

Overall, the order of the steroid $\mathrm{PCl}-\mathrm{NH} 3 \mathrm{MS}\left[\mathrm{M}+\mathrm{NH}_{4}\right]^{+}$/ $[\mathrm{MH}]^{+}$ratios (infinite to 0.03 as shown in Table 1 ) followed as $(5 \beta \mathrm{P}$-diAC, $5 \beta \mathrm{A}$-diAC) $>5 \alpha \mathrm{A}$-diAC $>$ E-AC $>11 \mathrm{KE}-\mathrm{AC}>\mathrm{DHEA}-\mathrm{AC}>5$ -androstanol-AC $>$ A-AC $>19 N E-A C>$ EpiA-AC $>(D H T-A C, 11-O H A-$ $3-A C)>(T-A C$, EpiT-AC), and is inversely related to their PA. The only compound in SM15-AC that yielded neither $\left[\mathrm{M}+\mathrm{NH}_{4}\right]+$ nor $[\mathrm{MH}]{ }^{+}$, but rather $\mathrm{M}^{+}$, was $\mathrm{Cne}$, a saturated steroid precursor, as shown in Figure $8 \mathrm{f}$ and resembles the EI MS in Figure 8d. In addition, because Cne has no hydroxyl groups, it is not acetylated during derivatization.

\section{Conclusions}

This work demonstrates GC $\times$ GC coupled to qMS as a potential new tool for steroid detection and profiling in complex urine extracts. When used in combination with additional investigative techniques, the high specificity of $\mathrm{GC} \times \mathrm{GC}$ - $\left(\mathrm{PCl}-\mathrm{NH}_{3}\right)$-qMS will be helpful for identification of unknown steroids in complex urine matrices. $\mathrm{PCl}-\mathrm{NH}_{3}$ produces simpler mass spectra and more abundant pseudo molecular ion mass spectra than El, allowing straightforward interpretation for molecular weight and characterization of steroid functional groups. The use of $\mathrm{PCl}-\mathrm{NH}_{3}$, along with El, potentially allows detection and identification of unknown compounds, such as designer steroids, that elute in unique retention spots in the $2 \mathrm{D}$ chromatogram, and potentially more easily interpretable than with traditional 1D GC-MS techniques.

\section{Acknowledgements}

This work was supported by the Partnership for Clean Competition (PCC) < http://www.cleancompetition.org > and NIH grant RR031264. We thank Dr Larry Bowers for many helpful discussions.

\section{REFERENCES}

[1] J. A. Vollmin. High resolution gas chromatography of urinary steroids on glass capillary columns. Clin. Chim. Acta 1971, 34, 207.

[2] W. R. Lusby, M. J. Thompson, J. Kochansky. Analysis of sterol esters by capillary gas chromatography-electron impact and chemical ionization-mass spectrometry. Lipids 1984, 19, 888. 
[3] R. Ahmadkhaniha, A. Shafiee, N. Rastkari, M. R. Khoshayand, F. Kobarfard. Quantification of endogenous steroids in human urine by gas chromatography mass spectrometry using a surrogate analyte approach. J. Chromatogr. B Analyt. Technol. Biomed. Life Sci. 2010, 878, 845.

[4] L. Dehennin, M. Ferry, P. Lafarge, G. Peres, J. P. Lafarge. Oral administration of dehydroepiandrosterone to healthy men: Alteration of the urinary androgen profile and consequences for the detection of abuse in sport by gas chromatography mass spectrometry. Steroids 1998, 63, 80.

[5] M. Donike. The detection of doping by means of chromatographic methods. Drug Test. Analysis 2011, 3, 15.

[6] M. Donike, K. R. Barwald, K. Klostermann, W. Schanzer, J. Zimmermann. The detection of exogenous testosterone. Int. J. Sports Med.1983, $4,68$.

[7] U. Mareck, H. Geyer, G. Opfermann, M. Thevis, W. Schanzer. Factors influencing the steroid profile in doping control analysis. J. Mass Spectrom. 2008, 43, 877.

[8] P. Van Renterghem, P. Van Eenoo, H. Geyer, W. Schanzer, F. T. Delbeke. Reference ranges for urinary concentrations and ratios of endogenous steroids, which can be used as markers for steroid misuse, in a caucasian population of athletes. Steroids 2010, 75, 154 (erratum in 75, 373.

[9] P. Van Renterghem, P. Van Eenoo, W. Van Thuyne, H. Geyer, W. Schanzer, F. T. Delbeke. Validation of an extended method for the detection of the misuse of endogenous steroids in sports, including new hydroxylated metabolites. J. Chromatogr. B Analyt. Technol. Biomed. Life Sci. 2008, 876, 225.

[10] F. Z. Stanczyk, N. J. Clarke. Advantages and challenges of mass spectrometry assays for steroid hormones. J. Steroid Biochem. 2010, 121, 491.

[11] M. K. Parr, G. Fussholler, N. Schlorer, G. Opfermann, H. Geyer, G. Rodchenkov, W. Schanzer. Detection of Delta 6-methyltestosterone in a 'dietary supplement' and GC-MS/MS investigations on its urinary metabolism. Toxicol. Lett. 2011, 201, 101.

[12] M. K. Parr, W. Schanzer. Detection of the misuse of steroids in doping control. J. Steroid Biochem. 2010, 121, 528.

[13] S. Christakoudi, D. A. Cowan, N. F. Taylor. Steroids excreted in urine by neonates with 21-hydroxylase deficiency: Characterization, using GC-MS and GC-MS/MS, of the D-ring and side chain structure of pregnanes and pregnenes. Steroids 2010, 75, 34.

[14] B. S. Mitrevski, J. T. Brenna, Y. Zhang, P. J. Marriot. Application of comprehensive two-dimensional gas chromatography to sterols analysis. J. Chromatogr. A 2008, 1214, 134.

[15] B. S. Mitrevski, P. Wilairat, P. J. Marriott. Comprehensive twodimensional gas chromatography improves separation and identification of anabolic agents in doping control. J. Chromatogr. A 2010, $1217,127$.

[16] B. S. Mitrevski, P. Wilairat, P. J. Marriott. Evaluation of World AntiDoping Agency criteria for anabolic agent analysis by using comprehensive two-dimensional gas chromatography-mass spectrometry. Anal. Bioanal. Chem. 2010, 396, 2503.

[17] A. I. Silva, H. M. G. Pereira, A. Casilli, F. C. Conceicao, F. R. A. Neto. Analytical challenges in doping control: Comprehensive twodimensional gas chromatography with time of flight mass spectrometry, a promising option. J. Chromatogr. A 2009, 1216, 2913.
[18] G. Purcaro, P. Q. Tranchida, P. Dugo, E. La Camera, G. Bisignano, L. Conte, L. Mondello. Characterization of bacterial lipid profiles by using rapid sample preparation and fast comprehensive twodimensional gas chromatography in combination with mass spectrometry. J. Sep. Sci. 2010, 33, 2334.

[19] E. Lukaszewicz, T. leda, Y. Horii, N. Yamashita, J. Falandysz. Comprehensive two-dimensional GC (GC $x$ GC) qMS analysis of tetrachloronaphthalenes in Halowax formulations. J. Environ. Sci. Health. Part A 2007, 42, 1607.

[20] P. Q. Tranchida, R. A. Shellie, G. Purcaro, L. S. Conte, P. Dugo, G. Dugo, L. Mondello. Analysis of fresh and aged tea tree essential oils by using GCxGC-qMS. J. Chromatogr. Sci. 2010, 48, 262.

[21] D. Sciarrone, P. Q. Tranchida, C. Ragonese, L. Schipilliti, L. Mondello. Multidimensional GC coupled to MS for the simultaneous determination of oxygenate compounds and BTEX in gasoline. J. Sep. Sci. 2010, 33, 594.

[22] M. S. B. Munson, F. H. Field. Chemical ionization mass spectrometry .I. General introduction. J. Am. Chem. Soc. 1966, 88, 2621.

[23] Y. Y. Lin. Identification of steroids by chemical ionization massspectrometry. Lipids 1980, 15, 756.

[24] J. B. Westmore, M. M. Alauddin. Ammonia chemical ionization massspectrometry. Mass Spectrom. Rev. 1986, 5, 381.

[25] T. Rezanka. Analysis of sterol esters from alga and yeast by highperformance liquid-chromatography and capillary gas-chromatography mass-spectrometry with chemical ionization. J. Chromatogr. 1992, 598, 219.

[26] T. Piper, U. Mareck, H. Geyer, U. Flenker, M. Thevis, P. Platen, W. Schanzer. Determination of C-13/C-12 ratios of endogenous urinary steroids: method validation, reference population and application to doping control purposes. Rapid Commun. Mass Spectrom. 2008, 22, 2161.

[27] Y. Zhang, J.H. Tobias, J.T. Brenna, Annual ASMS Meeting on Mass Spectrometry Related Topics Denver, CO. 2011.

[28] A. M. Galan Martin, J. I. Marino, M. P. Garcia de Tiedra, J. J. Marabe, M. J. Caballero Loscos, M. M. Marino. Determination of nandrolone and metabolites in urine samples from sedentary persons and sportsmen. J. Chromatogr. B Biomed. Sci. Appl. 2001, 761, 229.

[29] R. J. Auchus. Congenital adrenal hyperplasia in adults. Curr. Opin. Endocrinol. Diabetes Obes. 2010, 17, 210.

[30] M. Stanic, M. Nesovic. Congenital adrenal hyperplasia. Medicinski Pregled 1999, 52, 447.

[31] J. Homoki, J. Solyom, U. Wachter, W. M. Teller. Urinary-excretion of 17-hydroxypregnanolones in patients with different forms of congenital adrenal-hyperplasia due to steroid 21-hydroxylase deficiency. Eur. J. Pediatr. 1992, 151, 24.

[32] K. Homma, T. Hasegawa, E. Takeshita, K. Watanabe, M. Anzo, T. Toyoura, K. Jinno, T. Ohashi, T. Hamajima, Y. Takahashi, T. Takahashi, N. Matsuo. Elevated urine pregnanetriolone definitively establishes the diagnosis of classical 21-hydroxylase deficiency in term and preterm neonates. J. Clin. Endocrinol. Metab. 2004, 89, 6087.

[33] P. C. White, P. W. Speiser. Congenital adrenal hyperplasia due to 21hydroxylase deficiency. Endocr. Rev. 2000, 21, 245 (erratum in 21,550).

[34] P. E. Sottas, N. Robinson, O. Rabin, M. Saugy. The athlete biological passport. Clin. Chem. 2011, 57, 969.

[35] N. Robinson, M. Saugy, A. Vernec, P. E. Sottas. The athlete biological passport: An effective tool in the fight against doping. Clin. Chem. 2011, 57, 830. 